\title{
On the Complexity of the Universal Order in Vico's Establishing Principles
}

\author{
Taha Al-Douri 1,2 \\ 1 School of Architecture and Design, New York Institute of Technology, 1855 Broadway, New York, \\ NY 10023, USA; taldour@nyit.edu or tahaduri@gmail.com; Tel.: +1-971-50-737-3243 or +1-917-603-6098 \\ 2 International Institute for Advanced Studies in Systems Research And Cybernetics (I.I.A.S), \\ P.O. Box 3010, Tecumseh, ON N8N 2M3, Canada
}

Academic Editors: Josue Antonio Nescolarde Selva and Josep-Lluis Usó-Doménech Received: 30 December 2016; Accepted: 12 March 2017; Published: 3 April 2017

\begin{abstract}
In his seminal work The Principles of a New Science of the Common Nature of Nations (Principii di una scienza nuova d'intorno alla natura delle nazioni, published in 1725 then again in 1730 and posthumously in 1744), Giambattista Vico (Born in 1668) wrote to qualify the scientific to include the humanities and their complexity beyond the popular Cartesian circumscription within the laws of physics—divinely instituted and set in motion-in describing its phenomena. The work is, for one, a manifesto of the essential complexity inherent in universal order, and against a reduction of scholarship to the pure sciences, in which elimination is key. Vico proposed a structure that afforded the organic integration of the humanities within the laws of physics as parts of "a tree of knowledge" whose trunk branched out into a progression toward certainty, drawn out of the most fluid humanities at the roots, in an order of premise and conclusion. The tree metaphor is the juncture of early moments of disparity and interdependence between complexity, on the one hand, and certainty on the other. Starting at the unknown, the immeasurably immense ultimate uncertainty, perception is shaped through fear, self-protection and subject to survival instincts. And so, crude metaphysics makes the trunk rooted in "poetic wisdom" with a natural mixture of limited sensuous cognition and unlimited imagination—or one striving beyond the fetters of immediate reality, logic, ethics, economics and politics which are all poetic sciences to Vico-branch out. On the other side of those branches, physics extends into chronology and geography—-the most certain—in agreement that the faculties of the human mind, including imagination, may not be outside of physics: the trunk from whence all knowledge cometh, and by the laws of which life is governed. Past validating human uncertainty as a measure of complexity-not lack of knowledge-in scientific inquiry, key concepts in Vico's The New Science, such as imagination, reason, creativity and science, maintain pressing relevance to examining complexity today, enabling consideration of their relevance between Vico's time and today, while maintaining that the uncertainty of imagination and the pragmatism of physics are but facets of the equally plausible constitution of a universal order.
\end{abstract}

Keywords: Giambattista Vico; complexity; political theory; Law of Nature; governance

\section{Historical Backdrop}

"The first men were theological poets; and that all temporal institutions by nature have crude origins," [1] (Axiom 361) wrote Vico upon introducing Poetic Metaphysics. He referred to the first men as "stupid (stupidity (n.): 1540s, "want of intelligence," from Latin stupiditatem (nominative stupiditas) "dullness, stupidity, senselessness," from stupidus "confounded, amazed; dull, foolish." At various times, it also meant "lack of feeling or emotion" (1560s); "stupor, numbness" (c. 1600))", a term that left much to be desired in accounting for the passage from ignorance to knowledge along wonder, a state uncommon to the stupid. The noun form is stupor, as in lack of emotion, numbness or dullness; 
however, stupidus (Stupid (Adj.): 1540s, "mentally slow, lacking ordinary activity of mind, dull, inane," from Middle French stupide (16c.) and directly from Latin stupidus "amazed, confounded; dull, foolish," literally "struck senseless," from stupere "be stunned, amazed, confounded," from PIE *stupe"hit," from root *(s)teu- "to push, stick, knock, beat.") for being confounded or amazed, even as a result of a blow or a hit, suggested impact, even the passage from one state to another, to cross the synapse between inert ignorance and potent wisdom. Vico wrote [1] (Axiom 35): "Wonder is the daughter of ignorance. The greater the cause inspiring it, the greater the wonder," outlining a relationship of considerable complexity: conception and birth, integration, extraction, unity and severance all in one. Poetic wisdom would fulfill a dire need for consummating the complex relationship wherein the mind creatively aspires for an altered state driven by an ambiguous, subconscious impulse along a path enshrouded by the unknown. Imagination fertilizes the ignorant mind into birth, driving ignorance -inert and passive as a puddle of still water-through conception and labor (Ignorance (n.): c. 1200, "lack of wisdom or knowledge," from Old French ignorance (12c.), from Latin ignorantia "want of knowledge" (see ignorant). Ignoration (1832) has been used in the sense "act of ignoring."), for there is far more imagination in myth than there is knowledge. And while "all the histories of the pagan nations had mythical origins", Vico [2] had overlooked the forces setting things into motion as he named sorts of poetic wisdom where "the opposites do not contain each other ... the body which is hot is disposed to alter into a cold state.... Hot is never cold, and never contains any pieces of cold within it," [3] (pp. 74-75) explaining creativity as a work of imagination more than knowledge.

One frequently cited example of pagan nations is the Ancient Egyptians whose theological legacy was largely cumulative, coagulated upon the unification of Upper Egypt and Lower Egypt, and purely pagan, contradicting Otto Van Heurn (Van Heurn, Otto [also Otto Heurnius (1577-1652) Dutch physician and theologian] Pagan Philosophies of Antiquity. The editing translator, David Marsh, disputed the chronology of reference to this book in Vico's The New Science, stating that it echoed the work of a subsequent publication) that "Egyptians instructed Moses about divine rites before he introduced them to the Jews." The statement was seemingly made on grounds of precedence, in isolation of the essential disparity between the teaching of Moses and Egyptian pagan theology. The teachings of Moses would more readily be established as independent by origin and content than by questionable chronology. Vico, by authority of Flavius Josephus, as "irrefutable evidence" wrote that "the Jews were the first people in the world, and that in their sacred history they have truthfully preserved traditions dating from the beginning of the world" [1] (Axiom 54) as having lived all along "unknown to all nations," in a world that surrounded the Mediterranean Sea and defining livelihood through war and trade, both as old as there have been borders separating territories and defining states. The order of nations presented in The New Science sweeps across peculiarities; for example, Vico challenged Egyptian and Greek claims that they defined ancient theology when such claims remain largely true relative to pagan theology and related mythology. This sweeping tone to Vico's order of nations may have contributed little to furthering its subsequent relevance; yet within that very order live the elusive subtleties of telling a historic narrative well balanced between poetic reflection and factual accounts. Poetic reflection -a work of imaginative speculation-infused factual accounts with the complexity of Vico's new science, otherwise absent in the "sciences" from the time of René Descartes.

\section{On Vico's View of the Pagans}

“The Egyptians' mistaken belief in their own great antiquity sprang from the indeterminacy of the human mind, a property which often causes people to exaggerate immeasurably the magnitude of the unknown. In this, the Egyptians resembled the Chinese, who developed into a great nation isolated from all others, like the Egyptians until the reign of Psammeticus" [1] (Axiom 48). The claim to precedence- to Vico, a measure of Egyptians and Greeks being conceited ("Such great vanity for profound wisdom suited the Alexandrians, whose conceited nature caused them to be mocked as 'glory-hungry beasts.' Alexandria was an important trade center both for the Mediterranean and, through the Red Sea, for the Indian Ocean and the East Indies. "So when the Alexandrians heard 
merchants of various nations describe false deities scattered throughout the world, they believed that all of them had originated in Egypt," [1] (Axiom 47) is a matter of chronology that could be examined in the significant contributors to the advancement of knowledge, excepting-among the Near Eastern People - the peoples of Mesopotamia, who were absent in this context - Axiom 47 among othersremained so in Axiom 226 speaking of hieroglyphs as the language "that nations used in speaking during their early barbarism" including the Chinese as users of hieroglyphs when their writing as well as the writing of the Sumerians were distinctly non-pictorial, but character-based, the latter being in cuneiform characters. While China might conceivably be regarded as isolated amongst ancient nations, located to the eastern extremity of the inhabited world, the centrally located Egypt might not. Yet, isolated or not, accounting for the worst through magnified perception of the unknown would set out the path of wonder to knowledge, upon vying for certainty, in The New Science [4]. Yet, in doing so, he embraced the generally accepted notion of the time that non-European heritage was barbaric and so is generally inferior to Renaissance Europe, pledging allegiance in refined taste and sound legislation to Rome not to Greece, at least until the Eighteenth-Century debate on the origins of Western thought sweeping Europe from Carlo Lodoli [Carlo Lodoli (1690-1761) authored a long treatise on architecture that he did not publish, instead the content was incorporated in his disciple Francesco Algarotti's work Saggio sopra l'architettura (1757)] to Marc-Antoine Laugier's Essai Sur l'Art (Published in 1753, then again in 1755) and Giovanni Battista Piranesi in his polemical writings and elaborate folios such as Vedute Di Roma (Published in 1748) and Le Antichita Romane (Published in 1765 then 1835). The unquestioning acceptance of this popular view in Vico's work might have assuaged an otherwise stronger influence of The New Science as much as did his unpopular view at the time of what constituted "Science".

\section{The "New" in The New Science}

In the proposed sense of science, the birth of poetry [2], as a work of the imagination is no less the making of nature - and the laws of physics — than organized, fact-accounting texts such as laws, societal organizations and government. In describing a world conceived by "the human mind of pagan antiquity", Vico saw symbols that lined up the earth, the heavens and the path in between and have done so prior to Christianity—what he names "the true religion"—one of a number of disputable points that left unscathed the soundness of the thesis of natural birth being not only a rational act but also a work of imagining the beautiful and the sublime, as in poetic wisdom. "We have discovered that poetry was born sublime precisely because it lacked rationality" [1] (Axiom 384). The implication that poetry answered to "something arousing the feelings of wonder" is the closest Vico [5] comes to addressing the impulse bridging the mind gap between the inert state of ignorance and the charged and potent state of wonder, considering fascination to be a path naturally channeled in the pagan mind to divine intervention as "the nature of children, whom we see picking up inanimate objects in play and talking with them as if they were living persons" [1] (Axioms 37, 375). Childhood in this sense is a collective condition, one of nations, rather than the early stage of individual development, even though the example given is of individual nature. The parallel may be in a mind still free of preconceived notions of the natural world, prohibiting judgment of the inexperienced mind with no knowledge available to serve as grounds for comparison and deduction. The collective mind of pagan antiquity may still be comparable to that of a child in that convention had yet to be established. With reference to this point, the complexity of the mind and its creative faculties of learning, imagination and things in between remain intact and as rich as the most advanced and current of minds; the variation is one of information retained through experiencing the natural world and its governing laws of physics.

Notwithstanding instinct, which largely gives way to rational thinking in defining a mind responding to a natural order, and occasionally to poetry; it was instinct that accounted for variation among peoples and convention. One example-to elaborate on Vico's child attributing living qualities to inanimate objects would be a child's preference of cutlery and table instruments-such as dough 
whiskers, ladles, or electric grinders-over figurative toys, dolls or action figures. Imagining a face on a ladle's head, tilted akin to that of a doting parent, more readily lent itself to the freely interpretive imagination of a child than would the still features and glazed eyes on a doll. In a child's mind, purpose was outside and beyond immediate utility, even against it, free of literal expression, directness or the immediacy of the physical. In fact, contrary to a prevalent notion that coming of age is also natural growth in complexity, the fetters of convention arguably grow, as would an aggressive vine, exponentially binding imagination into stillness and reticence. And while wonder dies at the advent of convention, neither was possible without order, the foundation at the heart of human institution, itself conceived after a perceived order of the universe.

\section{Conclusively: Poetic Complexity between Reason and Imagination}

"The world of nations was clearly a human creation" [1] (Axiom 374), one that inextricably blends reason with imagination, and thus in which it is only possible for the created to be in the image of the creator. In his Poetics, what Aristotle [6] had named as poetry was a blend of fact and fiction or reason and imagination, conceived for reasons not unlike modern-day political analysis in that an account of fact may not suffice in expanding an apprehension of the meaning of events [7], or the interpretive potential of a narrative in the course of a larger stream of events, almost as a stream would pour into the course of a larger body of water. In other words, Aristotle presented poetry as an open horizon overarching beyond fact to probabilities and alternatives [6]. The aim of poetry is less about a presumed truth than about what could have been, what could be in the future or what could not have been or could not be. Poetry is thus less accountable for fact than it is for volumetric transcription of the bounds of possibility and probability based, in part, upon empirical evidence to start but not to conclude. Was the human mind in poetry a creator, the way God was? Without attempting to set creation apart from creativity [8], the one is an act and the other is a tendency. While creation is self-sufficient, an absolute entity in itself with no reference external thereto, independent of time and place, creativity is bound to natural laws and part of the physical world whose creativity is but an aptitude, relative to ability, skill, time and place, a tendency to become, relative to circumstance and all else. Marked along the passage of time, events acquire significance in the context of the narrative-beginnings or ends of wars, births and deaths of notable figures, further testifying to the impossibility of absolute judgment in history [9] being an account of complexity relative to circumstance.

Creation would entail authoring its makings from materials and their properties to the governing laws of physics, all of which lie well outside human ability. By this argument, originality is relative and making secondary, yet always inferior to creation. Let us remember that the laws of physics, according to Vico, as well as to philosophical inquiry in general were placed along the stem of the tree of knowledge from which knowledge-logic and imagination-would branch out. That is, no knowledge is possible outside the laws of physics and no imagination could exit their norms. Far from a simplifying factor, being bound within natural law is the very source of complexity where the flights of fancy might imagine seemingly beyond reality, only to find that the mind firmly placed within, is pressed into the economy of making do with the allowance of realism. The distinction between creation and creativity is intended to describe a probable transition from inert ignorance to potent wonder that would lead to creativity. The greater magnitude of such transition would then be from the presumed state of barbarism-disputable terms, if only for denying the natural complexity of early existence- - to a state of ingenuity implying active dissatisfaction, founded upon a vision and driven henceforth. This transition seemed absent from Vico's relating wonder to ignorance through seemingly an immaculate birth, without desire-reality recognized as essentially complex, often beyond historic accuracy—conception, or labor-probably being exponentially painful with complexity.

Imagination, explicitly to Vico and implicitly to Aristotle, is as firmly lodged within the laws of physics as knowledge is, since the mind is conceived within the makings of reality and will forever draw its inspiration there-from. Through both, knowledge and imagination, the mind constructed perceived representations that deepened and validated understanding of the universe in distinct paths, 
yet which are bound to intersect [9]. However, while the truth of knowledge is in content, the truth of imagination is in form and content in equal parts, thus relating the work of imagination less firmly to the natural world, or to the laws of physics [10]. The relation is as real and verified as that of a construct of knowledge, but it is less relevant to fully experiencing the constructs of imagination and far more complex. Complexity in the work of imagination is, in the latter, straddling conscious knowledge while extending its roots deep into wonder, hope and myth. The variety within unity that characterizes natural work is possible as long as the human mind is not involved, when multiplicity-a naive form of fragmentation-is introduced into a natural order that essentially rejects it. Reason, independent of natural order, often battled natural order with mental constructs unable to replicate natural harmony or fathom natural variety within unity [11]. Although the apparent opposition between the complexity in natural order yielding an essential and fateful unity in Divine creation, and the fundamental simplicity of human creativity found in the essential multiplicity in the makings of the human mind-that opposition-is seemingly a work of opposing wills, it is a work of a human mind vying to exit the laws of physics of which its very existence is made [12], and is therefore the making of all that the human mind will make, for the only way to conquer nature is to harmonize with nature.

Conflicts of Interest: The authors declare no conflict of interest.

\section{References}

1. Vico, G. New Science, 3rd ed.; Reprint with corrections of 1744, 1999, 2001, 2013; March, D., Translator; Penguin Books: Suffolk, UK, 2013.

2. Barfield, R. Vico's New Science. In The Ancient Quarrel between Philosophy and Poetry; Barfield, R., Ed.; Cambridge University Press: Cambridge, UK, 2011; Chapter 6.

3. Roeklein, R.J. Plato Versus Parmenides, The Debate Over Coming-Into-Being in Greek Philosophy; Lexington Books: Plymouth, UK, 2011.

4. Marshall, D.L. Vico and the Transformation of Rhetoric in Early Modern Europe; Princeton University Press: Princeton, NJ, USA, 2010.

5. Burke, P. Vico; Oxford University Press: New York, NY, USA, 1985.

6. Aristotle. Introduction to Aristotle; McKeon, R., Ed.; The Modern Library: New York, NY, USA, 1947.

7. Bayer, T.I. Vico's Pedagogy (1699-1707). New Vico Stud. 2008, 27, 39-56. [CrossRef]

8. Gianturco, E. (Translator) De Nostri Temporis Studiorum Ratione (1709), On the Study Methods of Our Time; Verene, D.P., Translator; Addendum: The Acadamies and the Relation between Philosophy and Eloquence (1737); Cornell University Press: Ithaca, NY, USA, 1990.

9. Berlin, S.I. Vico and Herder: Two Studies in the History of Ideas [Monograph]; The Hogarth Press: London, UK, 1976.

10. Samuelson, S. Joyce's Finnegans Wake and Vico's Mental Dictionary. New Vico Stud. 1999. [CrossRef]

11. Cornford, F.M. Plato's Cosmology, The Timaeus of Plato; translated with running commentary by Cornford, Francis MacDonald; Hackett Publishing Company: Indianapolis and Cambridge, IN, USA, 1997.

12. Taylor, J. (Translator) On the Most Ancient Wisdom of the Italians. Drawn out for the Origins of the Latin Language (1711); Yale University Press: New Haven, CT, USA, 2010. 